\title{
Public Selffocus and Sex Differences in Behavioral Self-Handicapping: Does Increasing Self-Threat Still Make It “Just a Man's Game?”
}

\author{
Edwerd R. Hirt \\ Sean M. McCrea \\ Indiana University \\ Charles E. Kimble \\ University of Dayton
}

The present study examined the effects of public self-focus and participants' sex on self-handicapping behavior. Research in the area of self-han dicapping has consistently shown that men al one tend to self-han dicap behaviorally. Becau se con ditions of public self-focus tend to make the evaluative implications of performance more salient, the authors hypothesized that peoplewould self-handicap more when they are self-focu sed (as opposed to other-focused). $M$ en and women were presented with an important intellectual evaluation and wereallowed to practice for the upcoming test as much as they wanted. Results showed that men self-handicap more when they are self-focu sed but women do not behaviorally self-handicap under self- or other-focu sed conditions. $\mathrm{H}$ eighten ed concern over possible failure in self-focused conditions appeared to be the critical mediator in encouraging self-han dicapping behavior among men.

M ost of the time, we try to attain and maintain a positive self-evaluation by performing the best we can and thereby win the approval of others. But sometimeswe are faced with the prospect of being unable to achieve the pinnacle of success (Berglas, 1986), especially in competitive circumstances. Under such circumstances, we may engage in self-protective strategies to salvage our positive self-evaluation. O ne class of these strategies is self-handicapping ( Jones \& Berglas, 1978).

Self-handicapping is defined as "any action or choice of performance setting that enhances the opportunity to externalize ( or excuse) failure and to internalize (or reasonably accept credit for) success" (Berglas \& Jones, 1978, p. 406). Hence, self-handicapping involves the strategic creation of a disadvantage for oneself prior to task performance. In this way, the self-handicapper can discount lack of ability as the cause for failure or augment ability as the cause for success (Kelley, 1972). Thus, self-handicapping helps one to maintain a positive self-evaluation.

Recently, a distinction has been made between two different kinds of self-handicapping: behavioral (or acquired) self-handicapping and self-reported (or claimed) self-handicapping (Arkin \& Baumgardner, 1985; Leary \& Shepperd, 1986). Behavioral self-handicaps refer to situations in which the self-handicapper actively constructs impediments that are likely to lower their chances for success. People have been shown to choose to take a performance-debilitating drug or ingest alcohol prior to an upcoming performance (Berglas \& Jones, 1978; Tucker, Vuchinich, \& Sobell, 1981) or even to decrease practice effort or preparation before an upcoming performance (Harris \& Snyder, 1986; Hirt, Deppe, \& Gordon, 1991). On the other hand, self-reported handicaps refer to situations in which the self-handicapper claims debilitating circumstances. People may report the presence of physical or psychological symptoms prior to performing, including health problems ( Mayerson \& Rhodewalt, 1988) or anxiety (Smith, Snyder, \& H andelsman, 1982). These claimsal so serve to excuse poor performance, although theymayor maynot be true. Clearly, these two forms of handicapping differ

\footnotetext{
Authors Note: The authors would like to thank George Bizer, Jenny Bradley, Brent Evans, Chris Fitch, Melissa H askin, Sharon O ser, Renee Sayegh, Amanda Shockey, and Kris Stakem for their assistance in conducting this study. Correspondence concerning this article should be addressed to Edward R. Hirt, Department of Psychology, Indiana U niversity, Bloomington, IN 47405; e-mail: ehirt@indiana.edu.
} 
in several respects (cost, believability, etc.) and should not be treated interchangeably. Indeed, $\mathrm{H}$ irt et al. (1991) found that participantsgiven the option to either behaviorally self-handicap (by withdrawing practice effort) or claim a handicap (by reporting high stress) clearly opted for the less costly self-reported handicap.

Sex Differences in

Self-H an dicapping

The distinction between self-reported and behavioral self-handicapping is particularly important with regard to sex differences in self-handicapping. Numerous studies (Berglas \& Jones, 1978; H irt et al., 1991; Shepperd \& Arkin, 1989b) have demonstrated that men are more likely to self-handicap than women, although these sex differences appear to emerge only with regard to behavioral self-handicapping. Many explanations have been offered for this sex difference in behavioral self-handicapping yet little advancement has been made in understanding the basis of this phenomenon.

One possible explanation for this difference is that women maybe less threatened by failure (Snyder, Ford, \& $H$ unt, 1985). This view would argue that men may have a stronger motivation to protect the self than do women (cf. Hirt et al., 1991). If women are in fact less threatened, they may not choose to engage in behavioral self-handicapping because of the potential costs of such a strategy. Behavioral self-handicapping involves actions that clearly reduce one's chances of success, whereas the effects of claiming a self-handicap on performance are less clear. If women are less threatened by potential failure, they may see behavioral self-handicaps as unnecessarily costly and not be willing to sabotage their chances for success byengaging in such self-destructive behavior. Men, on the other hand, if they experience greater threat, may be more willing to incur the costs of behavioral self-handicaps in the service of the attributional benefits they afford.

A second possibility is that men and women are equally threatened by failure but differ in the manner in which they deal with that threat. There are several possible reasons whymen and women might differ in the ways they choose to cope with potential failure. Men and women seem to differ in their beliefs about the roles of effort and ability in bringing about success, as well as the expected attributional benefits and interpersonal costs associated with behavioral self-handicapping. We discuss each of these points below, emphasizing how they might explain the different responses of men and women to threat.

Dweck and her colleagues ( Dweck \& Leggett, 1988) have pointed out that individuals vary in the extent to which they believe that ability is a fixed trait rather than something mutable. Rhodewalt (1994) found that chronic self-handicappers (as identified by the Jones and Rhodewalt [1982] Self-H andicapping Scale) and men in general are more likely to believe that ability is a fixed trait in academic settings. Thus, when faced with the prospects of failure, men may believe that effort cannot change their performance and are more willing to engage in self-handicapping to ambiguate the cause of their failure. Women, on the other hand, may actually increase their effort when threatened because they believe it will be helpful in improving their performance. These sex differences in beliefs about the efficacy of effort also are found among school-age children, indicating that they may be rooted in early socialization (cf. Cooper, Burger, \& Good, 1981). In fact, such differences may arise because the attributions made for male and female performances by others are quite different.

A sizable literature has found that women are often not afforded the same attributions for performance as men (Frieze, Parsons, Johnson, Ruble, \& Zellman, 1978). In a recent meta-analysis, Swim and Sanna (1996) found a consistent pattern of observer attributions to unstable causes, such as effort or luck, for failure on the part of men on masculine tasks but to ability for failure on the part of women on masculine tasks. This pattern also has been found in teacher attributions for grade school children (Dweck, Davidson, Nelson, \& Enna, 1978). If poor performances on the part of women are attributed to lack of ability even if effort is withheld or some other self-handicap is present, then the usefulness of engaging in behavioral self-handicapping for women also might be diminished.

Furthermore, research hasshown that behavioral selfhandicaps carry additional interpersonal costs. Because behavioral self-handicaps (e.g., withdrawing effort) are intentional actson the part of the performer, theyclearly implicate the self-handicapper as the cause of their own demise. Claimed self-handicaps, on the other hand, do not necessarily implicate the self-handicapper. They are unfortunate circumstances that befell the individual that may impair performance. The consequences of this distinction are particularly important in determining the reaction of others to the performer. In particular, behavioral self-handicaps can have important interpersonal consequences, such as dislike and lack of willingness to work with the handicapper on future tasks (Luginbuhl \& Palmer, 1991). Recently, Hirt, McCrea, and Boris (2000) found that women in particular viewed behavioral self-handicappers as irresponsible and self-destructive. These findings suggest that women may perceive the costs of behavioral self-handicapping (in terms of both performance and interpersonal dimensions) to be greater than do men. Thus, we have argued that women may not select behavioral self-handicaps because ( $a$ ) they may be less threatened by failure than 
are men or (b) they choose alternative ways of dealing with threat, given that they do not expect to gain the same benefits from self-handicapping as do men.

Public Self-Focus and

Self-H andicapping

Given that higher levels of threat may be the key to male behavioral self-handicapping, it is important to consider what variables lead to increased threat and higher levels of behavioral self-handicapping. Work by a number of researchers ( Berglas \& Jones, 1978; Kolditz \& Arkin, 1982; Mayerson \& Rhodewalt, 1988) indicates that conditions of noncontingent success are especially likely to elicit self-handicapping. These researchers argue that the uncertainty about one's own level of ability produced by such a manipulation (and uncertainty about one's ability to maintain a high level of performance in the future) encourages the use of selfhandicapping.

A second situational manipulation revolves around the characterization of the task. Research has demonstrated that when a task is characterized as important (e.g., diagnostic of some valued characteristic such as intelligence), participants ( particularly those expecting to perform poorly) are much more likely to self-handicap than when the task is unimportant (Shepperd \& Arkin, 1989a, 1989b). Thus, it appears that a manipulation that enhances the self-relevant implications of one's performance also increases the motivation to selfhandicap.

However, an additional situational variable that should affect the likelihood of self-handicapping is the presence of others who are able to evaluate the performance. Public situations have been shown to elicit more self-handicapping than truly private situations (Baumgardner, 1991; Kolditz \& Arkin, 1982). These findings indicate that self-handicapping may be motivated by impression management concerns, at least in some circumstances (Arkin \& Baumgardner, 1985; Kolditz \& Arkin, 1982; Luginbuhl \& Palmer, 1991; Shepperd \& Arkin, 1989b). The literature on public self-awareness seems to be particularly relevant to this point. Public self-awarenessoccurs whenever attention is directed toward the implications of one's behavior for other's evaluations of the self. Such situations have the dual nature of focusing attention on others as well as onto the self. The result of such shifting attention is that the individual should be more cognizant of the evaluative implications of a performance. To the extent that the individual is concerned with the impressions others will have of him or her following an important performance, self-handicapping is a more likely response.
Heightened concern with performance as a result of public self-awarenesscan be created bythe existence of a real or imagined audience. Within the self-awareness literature, such an audience often has been created through the use of a TV camera placed in front of participants (Carver \& Scheier, 1978; Davis \& Brock, 1975; Duval \& Wicklund, 1972; Kurosawa \& Harackiewicz, 1995). The presence of a camera has been found to have numerous effects on behavior, usually consistent with an increase in impression management concerns (Gibbons, 1990).

To date, no self-handicapping studieshave used a situational manipulation of public self-focus in this manner and examined its effects on self-handicapping. H owever, one study (Shepperd \& Arkin, 1989b) has investigated the effects of individual differences in public self-consciousness (cf. Fenigstein, Scheier, \& Buss, 1975) on self-handicapping behavior. Based on the Kolditz and Arkin (1982) argument that self-handicapping isprimarily in the service of self-presentational concerns, Shepperd and Arkin (1989b) found that people who were high in public self-consciousness ( people who are chronicallyattentive to themselves, especiallyon matters related to how others evaluate them) self-handicapped more than did people low in public self-consciousness. Thus, the evaluative implications of the task are likely to be greater for these individuals. We expect that induced public self-focus (using a camera) would affect self-handicapping in the same way as individual differences in public self-consciousness, by increasing the threat of an impending evaluation.

One limitation of Shepperd and Arkin's (1989b) results is that process measures were not included. Thus, the increased evaluative concern inherent in individuals who score high in public self-consciousness was not shown as a mediator of their subsequent self-handicapping. In the present study, we wanted to explore the processes by which public self-focus might be affecting self-handicapping behavior. We have argued that public self-focusincreasesthe evaluative implications of the test and the potential threat of performance feedback. This view is consistent with past findings on uncertainty and task importance as antecedents of self-handicapping behavior. H owever, the literature on self-focused attention hasrevealed a number of different effectsassociated with public self-focus. Those under public self-focusmay adhere more to the standards of a generalized other (Carver \& Scheier, 1981; Gibbons, 1990). Those believing they are unable to live up to such standards may resort to self-handicapping. The presence of others also may reduce expectations for success, either through increased uncertainty or the adoption of higher standards. Indeed, there appear to be several possible mediating mechanismsthat might be producing the effects of 
public self-focused attention on self-handicapping behavior. Thus, we included several additional measures intended to tap participants' expectations, standards, and fear of failure, as well as their beliefs about the upcoming performance, to investigate which of these possible mediating mechanisms might underlie any differences observed in self-handicapping behavior.

If public self-focus does increase the threat of an upcoming performance, it may provide a possible explanation for the sex differences in behavioral self-handicapping discussed earlier. In particular, greater responsiveness to public self-focus on the part of men may mediate sex differences in the use of behavioral self-handicaps. Sheppard and Arkin (1989b) obtained a main effect of gender in their study, such that men were more likely to self-handicap. H owever, their use of a personality variable ( public self-consciousness) rather than a situationallyinduced manipulation doesnot allow for a comparison of the causal effects of self-focuson each sex. Public self-focus may affect men and women in different ways. Public self-focus might increase the evaluative threat more for men than for women; alternatively, it might increase the evaluative threat equally for both men and women but motivate different behavioral responseson the part of men and women. In short, a situational manipulation of self-focus and the use of process measures allows us to test some important questions about the basis of the observed sex differences in the use of behavioral self-handicapping.

\section{The Present Study}

If one failsafter exerting a high amount of effort, then the failure implies that one lacks ability. In fact, self-worth theory indicates that the greatest shame is experienced when one fails while giving high effort (Covington \& O melich, 1979). Because people are most devastated by a demonstration of personal lack of ability, one of the most common ways to self-handicap isto exert low effort.

Given this logic, we used the behavioral self-handicap of effort withdrawal in the present experiment. Borrowing a paradigm used by Smith et al. (1982) and H irt et al. (1991), male and female participants were assigned to either a "practice matters" or "practice does not matter" condition. In the practice matters condition, participantswere told that their test scoreswould be affected by their amount of practice (i.e., practice improves test scores). In this condition, low amounts of practice are indicative of self-handicapping. In the practice does not matter condition, participants were told that amount of practice would not affect their test scores. Thiscondition servesas a baseline for comparison with the practice matters conditions. Thus, self-handicapping can be inferred to the extent that there is no difference between the practice matters and practice does not matter conditions.

Within each of the practice conditions, we manipulated public self-focus. We expected that participants in the public self-focus condition would be more likely to self-handicap (i.e., show reduced practice effort in the practice matters condition) than participants in the other-focus condition. Given past findings on sex differences (e.g., Hirt et al., 1991), we were reasonably confident that men would show greater evidence of behavioral self-handicapping ( and withdraw effort). H owever, it is less clear how conditions of increased public self-focus will affect women and men in general. For instance, it might be the case that the effects of induced public self-focus might influence behavior for men only. Alternatively, the effects of public self-focus might be more broad and override sex differences; it would be particularlyintriguing if women self-handicapped under conditions of public self-focus. Thus, the present study should provide insight into the nature of sex differences in behavioral self-handicapping. Second, the present study goes beyond past research by providing evidence of the mediating variables that may underlie the adoption of a self-handicapping strategy.

\section{METHOD}

\section{Overview}

Male and female participants were told they would be participating in a study of intelligence and would be completing a nonverbal intelligence test. Participants were assigned to either an other-focus condition, designed to direct their attention to purely external aspects of the situation, or a public self-focus condition, designed to direct attention to the presence of the experimenter as well as toward the self. Participants were then introduced to the nonverbal intelligence test and assigned to either a practice matters condition, in which practice presumably helpsone achieve an accurate measure of their intelligence, or a practice does not matter condition, in which practice does not appreciably change the diagnosticity of the test. Participants then completed a number of measures to assess their expectations and standards for performance, feelings about the test, and the perceived importance of the test. Participants were then given a chance to practice for the exam. The time they spent practicing as well as the number of practice items completed were recorded. As mentioned earlier, little practice in the practice matters condition (relative to the practice does not matter condition) is considered indicative of behavioral self-handicapping. 


\section{Participants}

Participants were 198 ( 95 men and 103 women) introductory psychology students at Indiana U niversity. Participants were run individually.

Procedure

After arriving, participantswere assigned to either the self-focus (SF) or other-focus (OF) condition. Participants in the SF condition were told that the experiment was examining the relationship between personality and general intellectual ability. They were then told that, for the duration of thestudy, they would be monitored using a camera in the participant's cubicle. Participants were told that the camera was being used to ensure that people gave honest and accurate responses during the experiment. Participants were shown the camera in the cubicle as well as the monitor in the control room to demonstrate that the camera was in deed working. Participants then completed a sentence-completion task and a personality questionnaire, designed to heighten self-attention. For the sentence-completion task, participants were instructed to complete sentences beginning with "I am ..." " with self-descriptive statements. Participants engaged in the sentence-completion task for 2 minutes. After the participants had completed the first measure (but before they indicated that they were done), the experimenter entered the cubicle to reinforce the notion that their behavior was being closely monitored. Participants were then given a personality questionnaire, in which they were asked to rate themselves on a number of trait dimensions. Participantswere given 4 minutes to complete this task.

Participants in the OF condition were told that the experiment was examining the relationship between impression formation and general intellectual ability. They were then asked to read a description of a fictitious person named Donald (cf. Higgins, Rholes, \& Jones, 1977) and to form an impression of him based on the information presented. Participants were given 2 minutes to form an impression of Donald. These participants were then given the same personality questionnaire as SF participants but were asked to rate Donald (rather than themselves) on the given trait dimensions. Participantswere given 4 minutesto complete thistask.

Participants in both conditions were then introduced to the Culture Fair Intelligence Test (CFIT) (Cattell \& Cattell, 1961). The experimenter explained the problem of cultural bias in intelligence testing and extolled the virtues of thisnonverbal test. The experimenter then went over several examples of how to answer the test questions. The particular CFIT test used was a series completion task. To increase the evaluative threat and uncertainty of their performance, participants were given a very difficult final example and all participants were told that their answer was incorrect (regardless of the answer they gave).

Participants were then told that they would be given 5 minutes to complete the 25 questions on the actual test. Theyalso were told that their test would be scored before the completion of the study. Participants were given the performance norms for the test; specifically, they were told that a score of 15 out of 25 was the average performance, with the top $10 \%$ scoring 19 and greater and the bottom $10 \%$ scoring 11 or less.

The experimenter then explained that participants would be given an opportunity to practice before taking the exam. Participants in the practice matters condition were told that practice was important to ensure that the test provided a measure of their true level of intelligence (cf. Hirt et al., 1991; Smith et al., 1982). Participants in the practice does not matter condition were told that practice did not affect performance on the test in any way. Participantsthen completed a number of manipulation check items assessing their memory for the instructionsabout practice as well asthe test. In addition, participants were asked to state their expected test score and the minimum test score with which they would be satisfied (both out of a possible 25). Participants also completed a set of nine items assessing their feelings about the test (e.g., importance, confidence, standards). Participants indicated their agreement with these statements using a 1 (not at all) to 7 (very much) scale.

$\mathrm{H}$ aving completed these measures, participants in the SF condition were reminded that they would be observed during the exam. Participants were then allowed to practice as long as they wished. The experimenter measured the amount of time the participant spent practicing before the exam.

Having completed the practice session, participants provided their expectationsfor their performance ( for a second time), their beliefs about the importance of practice, and their beliefs about the quality of the test. After completing these measures, participants were informed that they were in a control condition and would not have to take the exam but that they would need to wait $5 \mathrm{~min}$ utes before moving on to control for the amount of time others spent on the exam. After a minute, the experimenter returned and explained that theydid not have to wait, at which point participants were fully debriefed, thanked, and dismissed.

\section{RESULTS}

M anipulation Checks

Participants were asked a series of five true-false questions about the test. Accuracy for these questions was 
extremely high ( $M$ sranged from .88 to .99). In addition, participants' recall of the average score for the CFIT was excellent ( $99 \%$ correct). Thus, participants paid careful attention to the instructions regarding the test.

Participants' recall of the instructions regarding the effects of practice was also outstanding: 192 out of 194 participants correctly recalled the instructions about practice. Thus, participants did encode the instructions about practice accurately.

Step 1: Effects on Behavioral

Self-H an dicapping

O ur two indices of behavioral self-handicapping were the amount of time spent practicing and the number of practice problems solved. Given that these two indices were highly correlated, $r(193)=.84, p<.001$, we combined them to create a single practice measure $(\alpha=.91)$. To create this single index, we first did a log transformation of each measure (to reduce the skewness in these data), averaged the two measures together, and standardized the average. These data are presented in Table 1.

As the first step of the process analysis, a 2 (focus) $\times 2$ (practice instructions) $\times 2$ (sex) ANOVA was performed on the combined practice measure. Main effects were obtained for focus, $F(1,185)=5.00, p<.05$, practice instructions, $F(1,185)=14.17, p<.001$, and sex, $F(1$, $185)=10.33, p<.01$. O verall, women practiced more than men and individuals practiced more when instructed that practice matters or when in the other-focus condition. We also obtained significant Focus $\times \operatorname{Sex}, F(1,185)=4.80, p<.05$; Practice $\times \operatorname{Sex}, F(1$, $185)=14.51, p<.001$; and Focus $\times$ Practice $\times$ Sex interactions, $F(1,185)=5.70, p<.05$. To interpret the nature of these interactions, we did separate analysesfor men and women. For men, we obtained a main effect of focusand aFocus $\times$ Practice interaction (both Fs $>5.50$, ps $<.05$ ). In the practice matters condition, SF men practiced significantlyless ( $M=-.69)$ than did OF men $(M=.26), t(45)=$ $3.00, p<.01$. In the practice does not matter condition, neither SF nor OF men practiced much ( $\mathrm{M}=-.25$ and -.20 , respectively, $t<1$, ns). For women, on the other hand, we obtained onlya main effect of practice instructions, $F(1,95)=38.24, p<.001$. Women practiced significantly more in the practice matters condition ( $M=.59$ ) than in the practice does not matter condition ( $M=$ -.31). This pattern suggests that men alone show evidence of behavioral self-handicapping in the present study, consistent with past work ( $\mathrm{H}$ irt et al., 1991). H owever, thistendencyfor men to self-handicap wastrue only in the SF condition, in which men were particularlylikely to withdraw practice effort relative to all of the other conditions.
TABLE 1: Standardized Practice Scores as a Function of Foas, Practice Instructions, and Sex of Participant

\begin{tabular}{|c|c|c|c|c|}
\hline & \multicolumn{4}{|c|}{ Sex of Participant } \\
\hline & \multicolumn{2}{|c|}{ Male } & \multicolumn{2}{|c|}{ Female } \\
\hline & $\begin{array}{l}\text { Practice } \\
\text { M atters }\end{array}$ & $\begin{array}{c}\text { Practice } \\
\text { Does N ot } \\
\text { M atter }\end{array}$ & $\begin{array}{l}\text { Practice } \\
M \text { atters }\end{array}$ & $\begin{array}{c}\text { Practice } \\
\text { Does N ot } \\
\text { M atter }\end{array}$ \\
\hline Public self-focus & $\begin{array}{c}-.69 \\
(1.25) \\
n=22\end{array}$ & $\begin{array}{c}-.25 \\
(0.79) \\
n=25\end{array}$ & $\begin{array}{c}.65 \\
(0.31) \\
n=26\end{array}$ & $\begin{array}{c}-.36 \\
(0.98) \\
n=28\end{array}$ \\
\hline Other-focus & $\begin{array}{c}.26 \\
(0.91) \\
n=25\end{array}$ & $\begin{array}{c}-.20 \\
(0.66) \\
n=22\end{array}$ & $\begin{array}{c}.54 \\
(0.47) \\
n=29\end{array}$ & $\begin{array}{c}-.22 \\
(0.95) \\
n=16\end{array}$ \\
\hline
\end{tabular}

NOTE: Means for the combined practice measure were computed by first taking the $\log _{10}$ of both the time and number measures +1 (to eliminate skewnessin the data), standardizing the two indices, and taking the average of the two standard scores. Negative numbers on this combined practice measure reflect low practice effort. Standard deviations are indicated in parentheses.

Possible M ediators

A series of candidate-mediating variables was included in this study. The intercorrelations among these different potential mediators are presented in Table 2. Given that our primary interest wasin testing for possible mediators for the effects of focus on self-handicapping and the fact that we observed effects of the focus variable only for men, we next performed a series of separate ANOVAs on each of the candidate mediators to test for focus effects. These analyses were done for men only; however, in a final section, we explore mediators of practice behavior in women.

\section{Expectations}

Prior to the opportunity to practice, participants were asked about their expected score ( out of 25) on the CFIT test. An ANOVA performed on this measure revealed a marginal effect of focus, $F(1,90)=2.84, p<.10$. M en in the SF condition tended to have lower expectationsthan did men in the OF condition.

\section{Feelings}

Principal component analysis, with varimax rotation, of the nine feeling items revealed a three-factor solution, each factor having eigenvalues greater than 1 , accounting for $65.4 \%$ of the total variance. The first factor accounted for $32.9 \%$ of the total variance. It consisted of four items dealing with the importance of the exam ( $M=$ $15.80, \mathrm{SD}=5.55, \alpha=.81$; "I $\mathrm{t}$ is important to me that I do well," "I would be proud if I did well on this test," "I will be disappointed with myself if I perform poorly," "I am concerned about how others might regard my perfor- 
TABLE 2: Intercorrelations Among the Candidate Mediators

\begin{tabular}{lcccc}
\hline M easure & Exp & Fed 1 & Fed 2 & Feel 3 \\
\hline Expected score (Exp) & - & & & \\
Feeling measures & & & & \\
Importance (Feel 1) & .08 & - & & \\
$\quad$ Concern with failure (Feel 2) & $-.28^{* *}$ & -.07 & - & \\
$\quad$ Standards (Feel 3) & $.17^{*}$ & $.40^{* *}$ & -.18 & - \\
\hline
\end{tabular}

NOTE: $N=192$

$* p<.01 . * * p<.001$.

mance"). The second factor accounted for $21.3 \%$ of the total variance. It consisted of three items dealing with concern over possible failure and low expectations ( $M=$ $10.64, \mathrm{SD}=3.13, \alpha=.70$; "I am uncertain about how well I will do," "I am confident that I will perform well," "I expect to do poorly on this test"). The final factor accounted for $11.2 \%$ of the total variance. It consisted of two items dealing with internal standards for performance ( $M=11.86, S D=1.75, \alpha=.50$; "I set high standards for my own performance," "I want to do as well asI possibly can").

An ANOVA performed on the Importance factor revealed a marginally significant effect of focus, $F(1,90)=$ $3.47, p<.10$. Men in the SF condition tended to consider the test lessimportant than did men in the OF condition.

An ANOVA performed on the Concern With Failure factor revealed a highly significant effect of focus, $F(1$, $90)=36.65, p<.001$. Men in the SF condition expressed significantly greater uncertainty and concern about failure $(M=12.47)$ than did men in the OF condition ( $M=$ 9.26).

Analysis of the Standards for Performance factor also revealed a significant effect of focus, $F(1,90)=6.00$, $p<$ .05. Men in the SF condition expressed lower standards $(\mathrm{M}=11.26)$ than did men in the OF condition ( $\mathrm{M}=$ 12.17). Coupled with the data on the concern with failure measure, these data suggest that the lower standards reported by men in the self-focus condition may reflect an attempt to cope with potential upcoming failure at the task.

\section{Step 3: Testing M ediation}

Given that we had identified several possible mediators of the effects of self-focus on self-handicapping, we then performed a path analysisfollowing the procedures outlined by Judd and Kenny (1981a, 1981b). They propose that data are congruent with a mediational model when (a) the independent variables significantly predict the final outcome measure, (b) these variables also significantly predict the hypothesized mediating variable(s), and (c) the mediator significantly predicts the outcome measure when the independent variables are controlled.
The results of regression analyses on the combined practice measure indicated that the independent variables (focus, practice, Focus $\times$ Practice) significantlypredicted our behavioral self-handicapping index, $F(3,89)=$ $4.07, p<.01$, satisfying the Step $a$. Both the focus main effect $(\beta=.27)$ and the Focus $\times$ Practice interaction terms ( $\beta=-.23$ ) were significant. The results of regression analyses on the possible mediators (Step b) identified two potential mediators of the effects of self-focuson behavioral self-handicapping: concern about possible failure and lowered standards for performance. These two potential mediators were thus included in the final mediational model.

In thisanalysis (Step c), we added each of the two possible mediators (entered separately) to the Step a regression on the combined practice measure. When the concern about possible failure measure was added to the Step a equation, it washighly significant, $F(1,88)=11.78$, $p<.001(\beta=-.39)$. Moreover, the addition of this measure reduced the focus main effect $(\beta=.03)$ and the Focus $\times$ Practice interaction terms $(\beta=-.15)$ to nonsignificance, suggesting that concern about possible failure mediated the effects of self-focus on practice behavior. When the standardsfor performance measure was added to the Step a equation, it was not significant ( $F<1, n s)$, indicating that this variable did not mediate either the main or interaction effect of self-focus on practice.

\section{Step 4: Testing Interactional}

M ediation

To further explore the nature of the potential mediation, we performed a final regression examining possible interactional mediation. Judd and Kenny (1981a) identified two ways that an intervening variable can mediate the effects of independent variables on outcome variables: simple or interactional. When mediation issimple, the relation between the mediator and the outcome is the same across experimental conditions. When mediation is interactional, the independent variables and the mediator interact in affecting the outcome and the relation between the mediator and the outcome varies across experimental conditions. In thisregression, we included three additional terms, representing inter- 
actions between the potential mediator and each of the independent variable terms ( Focus $\times$ Concern, Practice $\times$ Concern, Focus $\times$ Practice $\times$ Concern). In this analysis, the Focus $\times$ Concern interaction term was significant, $F(1,86)=11.92, p<.001(\beta=.34)$. The concern main effect also remained significant, appearing even stronger $(\beta=-.53)$. Examination of the interaction revealed that men in the self-focus condition who felt particularly concerned about possibly failing at the test were the individuals most likely to withdraw practice effort and behaviorally self-handicap ( $\beta=-.87$ vs. $\beta=-.19$ for the other-focus condition). Figure 1 displays the final mediational model for men.

What A bout Women?

The results obtained for men provide clear indication that it is the enhanced concern with possible failure caused by conditions of public self-focus that mediated self-handicapping behavior. But what do these results say about the cause of the often-observed sex differences in behavioral self-handicapping? In the Introduction, we discussed two possibilities. One explanation suggests that women may simply not feel the same amount of threat as do men in performance situations. Such an explanation would predict that men and women may differ in their reported concern about possible failure but would imply that concern would still predict self-handicapping for both men and women. An alternative explanation suggests that both men and women experience threat in performancesituationsbut that their responses to such concerns is different. Men may engage in effort withdrawal to maintain perceptions of competence, whereas women may work harder to ensure good per formance. To distinguish among these two possibilities, we first performed a 2 (focus) $\times 2$ (practice) $\times 2$ (sex) ANOVA on the concern about failure measure to examine possible sex differences in perceived threat. In addition to the focus main effect, we obtained a significant Focus $\times$ Sex interaction, $F(1,185)=13.75, p<.001$. Although men expressed greater concern about failure in the SF asopposed to the OF condition ( $\mathrm{M} \mathrm{s}=12.48$ and 9.31 , respectively, $t>6.00, p<.001$ ), women showed no difference in concern across the two conditions ( $\mathrm{M} \mathrm{S}=$ 10.96 and 10.68, respectively, $t<1, n s$ ). Thus, it appears that women do not experience the same elevation of threat and concern about failure in public self-focusconditions that men do.

We then examined the extent to which concern about possible failure predicted practice behavior for women. An exploratory regression analysis in which we included all of the candidate mediators was performed on the female data. Thisanalysis reveal ed that the single predictor of practice behavior among women was the practice instructions $(\beta=-.53, t=6.07, p<.001)$. None of the can-

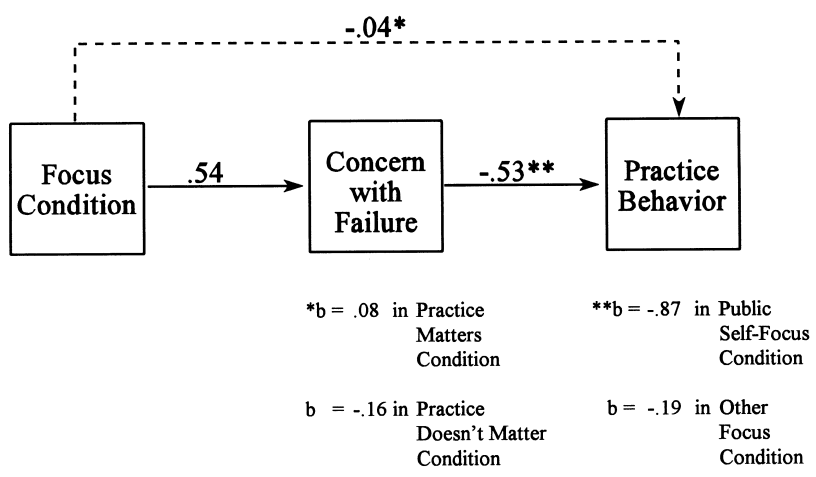

Figure 1 Final mediational model predicting thecombined practice measure for men.

NOTE: Solid lines reflect significant paths; dashed lines reflect nonsignificant paths. Path coefficientsfollowed bya single asterisk vary in magnitude as a function of practice condition. Path coefficients followed by two asterisks vary in magnitude as a function of focus condition. The unmediated path between focus and practice had a beta of .27 but varied as a function of practice condition. In the practice matters condition, the beta was .50; in the practice does not matter condition, the beta was .04 .

didate mediators ( most notably, the concern variable) or any interaction terms significantly contributed to the model. Thus, it is clear that women show a quite different response to threat than do men; increases in threat do not appear to influence practice behavior in women, a finding in stark contrast to the model obtained for men. H ence, our data provide support for both explanations of the sex difference in self-handicapping. Women appear to be less threatened and concerned about failure in public situationsthat invoke evaluation apprehension. In addition, women appear to respond to feelings of threat and concern not by withdrawing effort and behaviorally self-handicapping but by sustaining effort at preparing for the task to the extent that practice facilitates task performance.

\section{DISCUSSION}

O ur results add to the growing literature demonstrating that women do not engage in behavioral self-handicapping. In the present studies, women did not behaviorally self-handicap under either self-focus or other-focus conditions. Thus, even when the self-evaluative threat was made salient to women by the public self-focus manipulation, they (unlike the men) did not respond by self-handicapping. In the Introduction, we discussed two possible explanations for these sex differences in behavioral self-handicapping. First, we argued that men may perceive greater evaluative threat in performance situations than do women. Indeed, our data provide some support for this contention. Although men were less 
concerned about possible failure than were women in the other-focus condition, $\mathrm{M}=9.40$ vs. $10.69, \mathrm{t}(91)=$ $2.22, p<.05$, this pattern was reversed in the self-focus condition, $\mathrm{M}=12.51$ vs. $10.96, \mathrm{t}(98)=3.00, \mathrm{p}<.01$. Thus, men appeared to be particularly reactive to increased public self-focus in the present study.

Why might men feel greater threat in the public self-focus condition? Most studies examining self-focus have tended not to consider gender as a variable or have used single-sex designs. That men may be more responsive to public self-focus than are women may reflect the more general competitive orientation of men in performance settings. A good deal of research has noted that men are acutely focused on demonstrating their competence to others and are more driven by external standards (Gaeddert, 1985), whereas women are more closely focused on the accomplishment itself, leading to the use of intrinsic standards (Sutherland \& Veroff, 1985; Travis, McKenzie, Wiley, \& Kahn, 1988). Consistent with this logic, Baumeister, Hamilton, and Tice (1985) found that men responded aversely to audience expectations of success and experienced greater performance pressure than did women. Given that men have more at stake in public situations, they may be more inclined to engage in self-protective behaviors such as self-handicapping to avoid the threat of negative ability attributions.

But is the greater threat experienced by men in the public self-focus condition sufficient to explain the sex differences in behavioral self-handicapping? If this were the case, then we would expect that men and women would respond in the same way to increased threat in performance situations. However, the results of our mediational analyses indicated that this was clearly not the case.

Men experiencing enhanced threat withdrew practice effort and behaviorally self-handicapped, a finding consistent with past theorizing about self-handicapping (Berglas \& Jones, 1978). These researchers emphasized the pivotal role of uncertainty and concern about one's ability to perform well in producing self-handicapping. H owever, these critical constructs have rarely been measured in most self-handicapping studies, and few attempts have been made to document their mediational role. The present study represents an attempt to addressthismediational question and directly assessed a range of candidate mediating variables that might lead to self-handicapping. $O$ ur mediational analysesillustrate that the increased behavioral self-handicapping exhibited by men in the public self-focus condition was fully mediated by the corresponding increases in threat. Thus, it appears that the manipulation of public selffocus, similar to conditions of noncontingent success and task importance, produce behavioral self-handicapping by increasing the threat to self. The interactional mediation observed suggests that the combination of public self-focus and increased threat is particularly likely to result in effort withdrawal for men. Indeed, the pattern of results obtained for men provides direct empirical support for the predictions of the original Berglas and Jones (1978) self-handicapping model.

However, this same pattern did not hold true for women. Women experiencing greater threat did not behaviorally self-handicap; instead, they appeared to maintain a focus on doing the things necessary to perform well (i.e., practice) rather than protecting the self through effort withdrawal. Indeed, the only significant predictor of women's practice behavior was the practice instruction manipulation. Thus, a critical question iswhy women refused to self-handicap under these circumstances. In the Introduction, we discussed several possible reasons why women might not behaviorally handicap. O ne possible reason derives from work illustrating that women have different goals and implicit theorieson achievement tasks (cf. Dweck \& Leggett, 1988) than do men. If women tend to believe effort is the cause of success (as found by Rhodewalt, 1994), they may see potential failure as a signal that they need to work harder to improve. Conversely, if men tend to believe ability is the cause of success, theymay view potential failure as a diagnostic indicator that they lack ability and opt to self-handicap when threatened.

An alternative viewargues that women simply view the costs of behavioral self-handicapping to be greater than do men. There is considerable evidence that perceivers do not make the same attributions for failure in women as they do for men; thus, it may be that behavioral self-handicapping is a less effective strategy for women that doesnot afford them the same attributional benefits that it does men. Moreover, the use of behavioral selfhandicaps entails an important trade-off (cf. Baumeister \& Scher, 1988): Self-handicappers can excuse failure but incur significant interpersonal costs. Perceivers (particularly women) tend to dislike behavioral self-handicappers, view them as lazy and unmotivated, and choose not to have them as friends and study partners ( $\mathrm{H}$ irt et al., 2000; Luginbuhl \& Palmer, 1991). Thus, it makes sense that women may choose not to behaviorally self-handicap to avoid these negative interpersonal costs.

The present study was not designed to distinguish among these different explanations. Indeed, a number of intriguing questions must be answered if we are to be able to discern the nature of these sex differences in behavioral self-handicapping. One such critical question isthe extent to which these effectsare limited to specific types of tasks or specific domains. M ost of the studies investigating self-handicapping have focused on the 
academic domain, a domain in which men often are expected to excel (Gaeddert \& Facteau, 1990). Would these differences be equally prominent in other domains, such associal skills, athletic abilities, or artistic/ creative abilities? These questions await further research.

We believe another promising direction for future research on sex differences in self-handicapping resides in the distinction between behavioral and claimed self-handicaps. Given that women have been shown to claim self-handicaps, it would seem important to test whether increased threat would increase women's tendency to claim self-handicaps. Women may show a pattern of claiming self-handicaps in reaction to increased threat, paralleling the behavior of men given the option to behaviorally self-handicap. This result would indicate that women respond to threat in a manner similar to men when given a self-handicap that, for whatever reason, suits them. Such a finding would suggest that the locus of this sex difference lies in the type of self-handicap offered. As we have discussed, the perceived ratio of costs and benefits for behavioral and claimed self-handicaps appears to differ for men and women, which may explain why these differences exist. Currently, we are pursuing these questions in our lab.

In sum, we believe that the present research adds some valuable insight toward understanding sex differences in self-handicapping. Men and women not only appear to differ in the amount of threat they experience but also in their response to that threat. Whereas the responses of men fit well within the self-handicapping model first proposed by Berglas and Jones (1978), women appear to respond very differently in threatening evaluative situations. Thus, it appears that our approach to uncovering the nature of the sex difference has been turned on its head. Rather than trying to identify why men engage in such self-destructive behavior as behavioral self-handicapping, we might be better served by trying to understand why women do not.

\section{REFERENCES}

Arkin, R. M., \& Baumgardner, A. H . (1985). Self-handicapping. In J. H . H arvey \& G. W. Weary (Eds.) , A ttribution: Basicissues and applications (pp. 169-202). Orlando, FL: Academic Press.

Baumeister, R. F., H amilton, J. C., \& Tice, D. M. (1985). Public versus private expectancy of success: Confidence booster or performance pressure? Journal of Personality and Social Psychology, 48, 1447-1457.

Baumeister, R. F., \& Scher, S. J. ( 1988). Self-defeating behavior patterns among normal individuals: Review and analysis of common self-destructive tendencies. Psychological Bulletin, 104, 3-22.

Baumgardner, A. H. (1991). Claiming depressive symptoms as a self-handicap: A protective self-presentation strategy. Basic and Applied Social Psychology, 12, 97-113.

Berglas, S. (1986). The success syndrome: $\mathrm{H}$ itting bottom when you reach the top. New York: Plenum.

Berglas, S., \& Jones, E. E. (1978). Drug choice as a self-handicapping strategy in response to noncontingent success. Journal of Personality and Social Psychology, 36, 405-417.
Carver, C. S., \& Scheier, M. F. (1978). Self-focusing effects of dispositional self-consciousness, mirror presence, and audience presence. Journal of Personality and Social Psychology, 36, 324-332.

Carver, C. S., \& Scheier, M. F. (1981). The self-attention-induced feedback loop and social facilitation. Journal of Experimental Social Psychology, 17, 545-568.

Cattell, R. B., \& Cattell, A.K.S. (1961). Test of " $g$ ": Culture fair. Champaign, II: The Institute of Personality and Ability Testing.

Cooper, H. M., Burger, J. M., \& Good, T. L. ( 1981). Gender differences in the academic locus of control beliefs of young children. Jou rnal of Personality and Social Psychology, 40, 562-572.

Covington, M. V., \& O melich, C. L. (1979). Effort: The double-edged sword in school achievement. Journal of Educational Psychology, 71, 169-182.

Davis, D., \& Brock, T. C. ( 1975). U se of first person pronouns as a function of increased objective self-awareness and performance feedback. Journal of Experimental Social Psychology, 11, 381-388.

Duval, S., \& Wicklund, R. A. (1972). A theory of objective self-awareness. New York: Academic Press.

Dweck, C. S., Davidson, W., Nelson, S., \& Enna, B. (1978). Sex differences in learned helplessness: II. The contingencies of evaluative feedback in the classroom and III. An experimental analysis. Developmental Psychology, 14, 268-276.

Dweck, C. S., \& Leggett, E. L. (1988). A social-cognitive approach to motivation and personality. Psychological Review, 95, 256-273.

Fenigstein, A., Scheier, M. F., \& Buss, A. H . (1975). Public and private self-consciousness: Assessment and theory. Journal of Consulting and Clinical Psychology, 43, 522-527.

Frieze, I. H., Parsons, J. E., Johnson, P. B., Ruble, D. N., \& Zellman, G. L. (1978). Women and sex roles. New York: Norton.

Gaeddert, W. P. (1985). Sex and sex role effects on achievement strivings: Dimensions of similarity and difference. Journal of Personality, 53, 286-305.

Gaeddert, W. P., \& Facteau, J. D. (1990). The effects of gender and achievement domain on two cognitive indices of striving in personal accomplishments. Journal of Research in Personality, 24, 522-535.

Gibbons, F. X. (1990). Self-attention and behavior: A review and theoretical update. Advances in Experimental Social Psychology, 23, 249-303.

H arris, R. N., \& Snyder, C. R. ( 1986). The role of uncertain self-esteem in self-handicapping. Journal of Personality and Social Psychology, 51, 451-458.

H iggins, E. T., Rholes, W. S., \& Jones, C. R. (1977) . Category accessibility and impression formation. Journal of Experimental Social Psychology, 13, 141-154.

Hirt, E. R., Deppe, R. K., \& Gordon, L. J. ( 1991) . Self-reported versus behavioral self-handicapping: Empirical evidence for a theoretical distinction. Journal of Personality and Social Psychology, 61, 981-991.

H irt, E. R., McCrea, S. M., \& Boris, H. I. (2000) . Au dience reaction to selfhandicapping: A matter of who sees what in whom. Unpublished manuscript, Indiana University, Bloomington.

Jones, E. E., \& Berglas, S. (1978). Control of attributions about the self through self-handicapping strategies: The appeal of alcohol and the role of underachievement. Personality and Social Psychology Bulle tin, 4, 200-206.

Jones, E. E., \& Rhodewalt, F. (1982). Self-H andicapping Scale. Unpublished scale, Departments of Psychology, Princeton U niversity and University of Utah.

Judd, C. M., \& Kenny, D. A. ( 1981a). Estimating the effects of social interventions. Cambridge, UK: Cambridge University Press.

Judd, C. M., \& Kenny, D. A. (1981b). Process analysis: Estimating mediation in treatment evaluations. Evaluation Review, 5, 602-619.

Kelley, H. H. (1972). Causal schemata and the attribution process. In E. E. Jones, D. E. Kanouse, H. H. Kelley, R. E. Nisbett, S. Valins, \& B.Weiner (Eds.), Attribution: Perceiving thecauses of behavior ( $p p .151-$ 174). Morristown, NJ: General Learning Press.

Kolditz, T. A., \& Arkin, R. M. ( 1982) . An impression management interpretation of self-handicapping. Journal of Personality and Social Psychology, 43, 492-502.

Kurosawa, K., \& H arackiewicz, J. M. (1995). Text anxiety, self-awareness, and cognitive interference: A process analysis. Journal of Personality, 63, 931-951. 
Leary, M. R., \& Shepperd, J. A. ( 1986) . Behavioral self-handicapsversus self-reported self-handicaps: A conceptual note. Journal of Personality and Social Psychology, 51, 1265-1268.

Luginbuhl, J., \& Palmer, R. (1991). Impression management aspects of self-handicapping: Positive and negative effects. Personality and Social Psychology Bulletin, 17, 655-662.

Mayerson, N. H., \& Rhodewalt, F. (1988). The role of self-protective attributions in the experience of pain. Journal of Social and Clinical Psychology, 6, 203-218.

Rhodewalt, F. (1994). Conceptions of ability, achievement goals, and individual differencesin self-handicapping behavior: $0 \mathrm{n}$ the application of implicit theories. Journal of Personality, 62, 67-85.

Shepperd, J. A., \& Arkin, R. M. ( 1989a) . Determinants of self-handicapping: Task importance and the effects of preexisting handicaps on self-generated handicaps. Personality and Social Psychology Bulletin, $15,101-112$.

Shepperd, J. A., \& Arkin, R. M. (1989b). Self-handicapping: The moderating role of public self-consciousness and task importance. Personality and Social Psychology Bulletin, 15, 252-265.

Smith, T. W., Snyder, C. R., \& Handelsman, M. M. (1982). On the self-serving function of an academic wooden leg: Test anxiety as a self-handicapping strategy. Journal of Personality and Social Psychology, 42, 314-321.

Snyder, C. R., Ford, C. E., \& H unt, H . A. (1985, August) . Excusemaking: A look at sex differences. Paper presented at the 93rd Annual Convention of the American Psychological Association, Los Angeles.

Sutherland, E., \& Veroff, J. (1985). Achievement motivation and sex roles. In V. E. O 'Leary, R. K. Unger, \& B. S. Wallston (Eds.), Women, gender, and social psychology (pp. 101-128). Hillsdale, NJ: Lawrence Erlbaum.

Swim, J. K., \& Sanna, L. J. ( 1996). He's skilled, she's lucky: A metaanalysis of observer's attributions for women's and men's successes and failures. Personality and Social Psychology Bulletin, 22, 507-519.

Travis, C. B., McKenzie, B., Wiley, D. L., \& Kahn, A. S. (1988). Sex and achievement domain: Cognitive patterns of success and failure. Sex Roles, 19, 509-525.

Tucker, J. A., Vuchinich, R. E., \& Sobell, M. B. (1981). Alcohol consumption as a self-handicapping strategy. Journal of A bnormal Psychology, 90, 220-230. 